\title{
Una Iglesia para ultramar: el concordato de 1851 y su (no) aplicación en las Antillas españolas*
}

\author{
A Church for Overseas: The concordat of 1851 \\ and its (non) application in the Spanish Antilles
}

\section{Consolación FERnÁNDEZ MELLÉN}

Universidad del País Vasco

consolacion.fernandez@ehu.eus

\begin{abstract}
After the signing of the Concordat of 1851 the Spanish Overseas Churches lived in an exceptional situation. As they were not included in the Concordat, the Churches in these territories were still subject to the «Patronato real» and the Laws of the Indies until their independence in 1898. In this general context, the article analyzes the main problems that hampered the normal administration of the Church in the Spanish Antilles, particularly in Cuba, from 1836 onwards. It documents the unsuccessful efforts of the apostolic nuncio in Madrid to give the Church in the Spanish Antilles a solution in the framework of a concordat. However, Madrid saw the inclusion of the Overseas Churches in its articles as a cession of its privileges.
\end{abstract}

Keywords: Concordat of 1851; Holy See; royal patronage; Cuba; bishop; vicar seat vacant; regular orders.
Resumen: Tras la firma del concordato de 1851 las Iglesias del Ultramar español vivieron una situación de excepcionalidad. Su no inclusión en el Concordato supuso que las Iglesias de estos territorios continuaran sometidas al patronato real y a las Leyes de Indias hasta la independencia de 1898. En este contexto general, el artículo analiza los principales problemas que desde 1836 obstaculizaron la normal administración de la Iglesia en las Antillas españolas, particularmente en Cuba, y las gestiones infructuosas del nuncio apostólico en Madrid por darles una respuesta en el marco de un Concordato, donde la pretendida inclusión de las Iglesias Ultramarinas fue leído por Madrid como una cesión de sus regalías.

Palabras clave: Concordato de 1851; Santa Sede; Patronato; Cuba; obispo; vicario en sede vacante; ordenes regulares.

* El presente artículo es fruto de las investigaciones realizadas durante el Programa Posdoctoral de Perfeccionamiento de Personal Investigador Doctor del Gobierno Vasco (2014-2016). 


\section{EL PROBlema DE LAS SEDES VACANTES}

Tras la muerte de Fernando VII, las relaciones oficiales entre España y el Vaticano quedaron oficialmente rotas por la negativa de Roma a reconocer a Isabel II como reina de España ${ }^{1}$. Desde 1836 el estado de las diócesis ultramarinas fue agravándose como consecuencia de la desaparición de sus obispos. Uno de los primeros problemas al que dio lugar la ruptura de relaciones fue que la Santa Sede no admitió la presentación real de candidatos a las sedes episcopales vacantes. Hacerlo significaba admitir los derechos de patronato de Isabel II y se receló que, por extensión, este acto fuese interpretado como un reconocimiento de la legítima soberanía de la reina ${ }^{2}$. La consecuencia lógica fue que las sedes vacantes se prolongaron y en su lugar los cabildos nombraron vicarios generales a sujetos que muchas veces les fueron indicados por las autoridades políticas del territorio. Estas elecciones provocaron la división en facciones de los cabildos: por un lado entre aquellos capitulares que en virtud de los derechos de patronato defendieron el que los vicarios electos ejercieran la administración de la diócesis con la sanción real y sin la institución canónica y, por otro, aquellos que antepusieron la rigurosa observancia de los sagrados cánones y de la disciplina eclesiástica. Todo ello alteró la pacífica convivencia de los cuerpos catedralicios y obstaculizó el normal desarrollo del gobierno y de la vida diocesana.

1 La relación diplomática entre Roma y Madrid en este periodo fue sólo un peón más en la partida de ajedrez que se jugó en el seno de la política internacional europea, donde las potencias se debatieron entre las posiciones enfrentadas que representaban la Francia de Napoleón III y la Austria del príncipe de Metternich. Dependiente de las garantías que la política y el ejército austríaco ofrecían a la autoridad del Papa y a la unidad territorial de los estados pontificios, particularmente como consecuencia de las revoluciones liberales de 1831 en el centro de la península italiana, Gregorio XVI en sintonía con la postura austríaca respecto a la cuestión sucesoria española se negó a reconocer a Isabel II como reina de España. Desde 1836 y hasta 1844 las relaciones entre España y el Estado pontificio se desarrollaron sólo en el plano extraoficial y limitadas a casos de conciencia. A partir de 1845 éstas comenzaron a retomarse entre el representante del Estado español en Roma, José Castillo y Ayensa, y el cardenal secretario de Estado, Luigi Lambruschini. Tras un largo periodo de negociaciones, de avances y retrocesos, finalmente el restablecimiento oficial de las relaciones quedó sellado con la firma y posterior confirmación del Concordato español de 1851 por Isabel II y Pío IX (Alberto Mario BANTI, Il risorgimento italiano, Laterza, Roma-Bari, 2004, pp. 49-74; Rogert AUBERT, La prima fase del liberalismo cattolico, en Hubert JEDIN [coord.] Storia della Chiesa, VIII/1, Jaca Book, Milano, 1977, pp. 19-25). Sobre las relaciones diplomáticas entre España y Roma vid. Vicente CÁRCEL ORTÍ, Un siglo de relaciones diplomáticas entre España y la Santa Sede, en Anuario de Historia Contemporánea, 25 (2009), pp. 313-331.

2 Sobre la preconización de obispos para las diócesis españolas vid. Vicente CÁRCEL ORTÍ, Los nombramientos de obispos en España durante el pontificado de Pí IX. Primera parte: 1846-1855, en Analecta Sacra Tarraconensis, 72 (1999), pp. 319-488. 
En 1833 Fernando VII presentó como administrador de la diócesis de La Habana al arzobispo exiliado de Guatemala, fray Ramón Francisco Cassaus. La muerte del monarca y las tensas relaciones entre Roma y Madrid paralizaron el expediente de la institución canónica, sin que ello fuera impedimento para que Cassaus entrase a ejercer las funciones de administrador ${ }^{3}$. Apenas tres años más tarde, con motivo de la finalización del plazo de las facultades solitas, el arzobispo de Guatemala recurrió a la Santa Sede solicitando la prórroga de éstas y otras facultades ${ }^{4}$. La solicitud puso en una grave tesitura a la Santa Sede: la inexistencia de relaciones diplomáticas oficiales entre los dos estados no podía pesar más a ojos de la Santa Sede que el grave problema de los concubinatos en los territorios de ultramar; sin embargo, tampoco podía conceder la prórroga a un administrador que -como hemos visto- careció de institución canónica. Por el rescripto pontificio de 24 de febrero de 1836, Gregorio XVI instituyó de motu propio administrador apostólico a Cassaus retentu archiepiscopato y le prorrogó por diez años las solitas ${ }^{5}$. El documento pontificio no hizo referencia a la presentación real como administrador del arzobispo de Guatemala, aun así -probablemente la consideración de las mismas circunstancias que habían compelido a Roma a conceder el documento- hizo considerar al Tribunal Supremo de España e Indias la conveniencia de darle el pase: la real cédula auxiliatoria de agosto de 1839 ordenó dar posesión a Cassaus como administrador de la referida diócesis y mandó escribir una nota aclaratoria al margen del breve pontificio explicando que éste no podría alegarse:

[...] como ejemplo en perjuicio de los derechos incontestables e imprescriptibles del patronato que ha ejercido, ejerce, y tiene resuelto ejercer en adelante la suprema autoridad temporal depositada en los reyes de España para la presentación de todos los prelados; así como tampoco han de servir de ejemplo cualesquiera otras cláusulas del mismo breve que pudieran entenderse en un sentido capaz de causar novedad en la disciplina y prácticas observadas en las iglesias de Indias por lo tocante a su gobierno $[\ldots]^{6}$

3 VATICANO, ARCHIVIO DELLA CONGREGAZIONE DEGLI AFFARI ECCLESIASTICI ETRAORDINARI [=AA.EE.Ss], A. III. América. Guatemala, fasc. 513, nº 11. Copia de la real cédula auxiliatoria de la regente María Cristina, Madrid, 21 de agosto de 1839, ff. 93r-v.

4 Las conocidas como solitas son las facultades apostólicas que desde 1770 los diferentes papas concedieron y prorrogaron a los obispos americanos para dispensar los impedimentos matrimoniales a fin de evitar los concubinatos. Las largas distancias que separaban estos territorios de Roma y los altos costos del viaje y de los trámites disuadieron a muchas parejas de solicitar esta dispensa $\mathrm{y}$ a decidirse por una vida en concubinato.

5 AA.EE.SS, A. III. América. Guatemala, fasc. 513, nº 11. Rescripto de Gregorio XVI, Roma, 24 de febrero de 1836, ff. 86r-87r.

6 Ibid. Real cédula auxiliatoria de la regente María Cristina. Madrid, 21 de agosto de 1839, ff. 93r. 
Así mientras, por un lado, se regularizó la situación de Cassaus como administrador y se protegieron los derechos de patronato de la reina, un nuevo frente se abrió en el arzobispado de Santiago de Cuba, que amenazó con provocar un cisma y cuyas consecuencias se prolongaron durante más de una década. En 1837 para evitar la orden de extrañamiento de los reinos que el gobierno había dado contra él por las sospechas de carlismo, el arzobispo de Santiago de Cuba, fray Cirilo Alameda y Brea, se fugó de la isla. Antes de ausentarse, Alameda dejó nombrados como gobernadores eclesiásticos de la diócesis a Francisco Delgado y a Miguel de Herrera ${ }^{7}$. La nómina no fue reconocida por el cabildo, que, por su parte, en un acto que desconocía la autoridad del arzobispo prófugo y que significaba la asunción de las facultades de cabildo en sede vacante, cesó a los gobernadores eclesiásticos nombrados por aquel. Y eligió a los sujetos insinuados por el capitán general Miguel Tacón, los teólogos Diego José Batista, cura párroco de Bayamo, y a José Delgado, capellán de artillería en Santiago de Cuba, que desde entonces fueron investidos con la jurisdicción espiritual y contenciosa respectivamente ${ }^{8}$. Al conocer la noticia, desde su exilio londinense, Alameda trató de hacer prevalecer sus facultades y jurisdicción arzobispales adoptando una doble estrategia de acción. Mientras, por un lado, apeló a la Santa Sede en defensa de sus derechos y contra lo que consideró una usurpación del cabildo, por otro, paralelamente censuraba a los miembros del cabildo que habían intervenido en la elección de gobernadores «usurpadores», autorizó al cuerpo catedralicio en pleno para que:

[...] por una vez y sin perjuicio de lo prevenido en los estatutos de esa nuestra Iglesia, nombrara en nuestro nombre y por la facultad que le concedemos los gobernadores de nuestra diócesis, escogiéndolos entre los eclesiásticos más beneméritos por su ciencia y sus virtudes y, si esto no les es permitido hacer, le autorizamos para que reconociendo las solitas, obre según ellas en los casos en ellas prevenidos [.... ${ }^{9}$

7 Sobre este episodio remito a la tesis de Santiago HIGUERAS DE ANCOS, que será defendida en los próximos meses en la universidad de Toledo con el título [provisional] De la Facción a la monarquía constitucional: el cardenal fray Cirilo Alameda y Brea (1781-1872). Este estudio aborda la biografía y carrera de este polémico personaje. Agradezco al autor que me haya facilitado su lectura. Salvo en aquellos casos en los cuales se indique lo contrario, todas las informaciones referidas al arzobispo Alameda, a la elección de los administradores eclesiásticos de Santiago de Cuba y sus consecuencias están tomados del epígrafe correspondiente de la referida tesis de Higueras de Ancos.

8 AA.EE.SS, Spagna I, pos. 196, fasc. 50. El capitán general Miguel Tacón a Francisco Delgado, La Habana, 31 de agosto de 1837, f. 44 r; acta del cabildo metropolitano de Santiago de Cuba, 18 septiembre de 1837 , ff. 44r-45r.

9 Ibid. Oficio de fray Cirilo Alameda al cabildo de Santiago de Cuba, Londres, 15 de febrero de 1838, ff. 45r-45; carta de fray Cirilo Alameda a Gregorio XVI, Londres, 14 de febrero de 1838, ff. 43 r-v. 
El nombramiento del nuevo gobernador recayó en el arcediano de Toledo, Juan Pacheco, nuevamente un sujeto «insinuado» por la autoridad del capitán general en una propuesta con la cual el gobierno de Madrid quiso evitar que la elección recayese en un miembro del cabildo natural de la isla que hubiera significado seguir alimentando el conflicto y en quienes la metrópoli tenía poca confianza ${ }^{10}$. La elección no fue bien recibida por la Santa Sede, que desde un primer momento consideró ilegítimo al nuevo vicario e insistió en la legalidad canónica de la elección hecha por fray Cirilo en Delgado ${ }^{11}$.

Las consecuencias que supuso la nómina del nuevo gobernador de Santiago de Cuba transcendieron las fronteras de la propia diócesis, cuando en noviembre de 1845, tras la muerte de Cassaus, arzobispo administrador del obispado de La Habana, los cuatro miembros del cabildo habanero, divididos en dos facciones, no consiguieron ponerse de acuerdo en la elección del vicario capitular y gobernador de la diócesis. Tras las primeras votaciones, el expediente fue remitido al gobernador eclesiástico de Santiago de Cuba, a la sazón Juan Pacheco ${ }^{12}$, quien nombró al maestrescuela Pedro Mendo. Mendo había sido el provisor y vicario general de Cassaus desde 1840 y había ejercido las facultades episcopales durante la enfermedad del arzobispo administrador ${ }^{13}$. La elección de Pacheco no debió ser lo esperado por aquellos capitulares que remitieron el expediente a Santiago (probablemente con el objetivo de ver satisfechos sus propios intereses). Sin embargo, en este caso las dudas que pesaban sobre la legitimidad del propio gobernador de Santiago de Cuba fueron muy convenientes para los opositores de Mendo. Su nombramiento como vicario en sede vacante de La Habana emanaba de una autoridad considerada intrusa, lo cual, desde el punto de vista canónico, significaba que todo todos los actos que emanasen de su gobierno eran nulos. Este hecho dio argumentos a la facción contraria a Mendo para oponerse a su elección, no obstante que, como el mismo vicario escribió, había sido elegido por unanimidad en el cabildo:

[...] Aún no levantada la última sesión de escrutinio electoral, tomó uno de los votantes la palabra y dijo: pido al cabildo tome en consideración y resuelva quién ha de ejercer la jurisdicción capitular hasta que todo se haya terminado. Admitióse

10 Santiago Higueras DE ANCOS, De la Facción a la monarquía..., op. cit.

11 AA.EE.SS, Spagna I, pos. 285, fasc. 75. Ponencia estampa «Spagna. Varie istanze del Governo» de la Congregación de Asuntos Eclesiásticos Extraordinarios presentada en la sesión de 28 de noviembre de 1845 [numeradas sólo las primeras páginas a partir del f. 92 r].

12 Ibid., pos. 332, fasc. 93. Carta de Pedro Mendo [sin destinatario: ¿Pío IX?], Madrid, 27 de enero de 1849 , ff. 42 r- 44 r.

13 Ibid., pos. 288, fasc. 78. Edicto de Juan Pacheco, gobernador eclesiástico de Santiago de Cuba, Santiago de Cuba, 29 de noviembre de 1845, ff. 91r-92r. 
la proposición, procedióse a la votación y por unanimidad fui nombrado y elegido. Este hecho debe estar consignado en las actas capitulares. Autorizado ya de este modo por una resolución tan enérgica y decisiva, según la marcha jurisdiccional que me había propuesto, sin cuidar de otra cosa que de elevar a S.S. estos hechos, persuadido que si de ellos se hubiera podido alegar alguna infracción, no tenía duda que se hubiera corregido inmediatamente $[\ldots]^{14}$

La nómina de Mendo alteró los propios equilibrios del cabildo y abrió un periodo de abierto enfrentamiento con algunos miembros del cuerpo catedralicio. La gravedad de los hechos preocupó igualmente a Madrid y a Roma. El propio Mendo denunció esta situación ante la Santa Sede en un informe donde interpelaba a Gregorio XVI a:

[...] ayudarme con vuestros capitulares, salidos de los institutos religiosos, donde profesaron la abnegación de si mismos, es la que les ha hecho entrar en el mundo y, como si quisieran desquitarse del hábito de humildad y recogimiento en que debieron vivir antes, no se ruborizan de mostrar a la faz del público sus des[a]compasadas aspiraciones. Y no pareciéndoles bastante el grandor de ellas, todavía las ensanchan más y más, ayudándose de las turbulentas e inquietas pasiones de la política [...] Se han erigido en cabildo (contra mi voluntad, siendo yo el presidente) siempre y cada vez que les place, me han lanzado de la sala capitular con la mayor osadía, y ha llegado su avilantez hasta el extremo de amenazar que harán valer con el puñal la fuerza que quieren imponer con sus pretendidas razones [...] No es mi persona la que en estos debates sufre: es sí la autoridad que ejerzo $[\ldots]^{15}$

\section{II. «RES ECCLESIASTICAS ORDINANDAS»: LA PRECONIZACIÓN DE LOS PRIMEROS OBISPOS DE ULTRAMAR}

La resolución de ambos expedientes, el de la nómina del vicario de Santiago de Cuba y la del de La Habana, corrió en paralelo al proceso de normalización de las relaciones entre Roma y Madrid, que se impulsó a partir del gobierno del general moderado Narváez. Con este fin, desde 1845 el enviado extraordinario de España en Roma, José Castillo y Ayensa, inició las negociaciones que, además de acordar puntos como el de la venta de los bienes del

14 Ibid., pos. 332, fasc. 93. Carta de Pedro Mendo [sin destinatario: ¿Pío IX?], Madrid, 27 de enero de 1849 , ff. 43r. [subrayado en el original]

15 Ibid., pos. 288, fasc. 78. Pedro Mendo a Gregorio XVI, La Habana, 27 de enero de 1846, ff. 80r$80 \mathrm{v}$. 
clero que se había realizado durante el anterior gobierno o el proyecto para una dotación del culto y clero, tuvieron por objetivo dar respuesta al problema de la nómina de los vicarios en sedes vacantes y la presentación de obispos para la diócesis de ultramar.

La Santa Sede sabía que la adhesión de fray Cirilo Alameda a la causa carlista era un serio obstáculo para el regreso del arzobispo a su diócesis y la dificultad de hacer valer los derechos de Francisco Delgado como legítimo gobernador del arzobispado frente a un vicario, Pacheco, que consideró «intruso ${ }^{16}$. En una decidida prueba del interés de Gregorio XVI en sostener los derechos de Delgado, el 27 de octubre de 1845 el pontífice dirigió una carta al gobernador donde le confirmó:

[...] las facultades que le habían sido dadas por el señor arzobispo de Cuba como su vicario general y le ha mandado reasumir y continuar en el gobierno de aquella diócesis hasta que dure la ausencia de su prelado. Por otro lado, deberá gobernarla siempre en nombre, o sea como vicario del mismo arzobispo, así como exigen las reglas canónicas $[\ldots]^{17}$

La carta fue entregada a Castillo y Ayensa, que la recibió junto con otra nota donde el papa concedía al gobierno de Madrid la gracia de preconizar los obispos para las diócesis vacantes de ultramar. Meses más tarde, el enviado explicó al primer secretario de Estado las razones que le habían llevado a aceptar el rescripto pontificio, cuando aún en Madrid se discutía en el ministerio de Gracia y Justicia sobre la fórmula que debía exigirse a los documentos pontificios que delegasen las facultades a los vicarios en sede vacantes:

[...] habiéndoseme entregado la carta de S. $\mathrm{S}^{\mathrm{d}}$ al mismo tiempo que la nota en que se nos hacía la importantísima concesión de los obispos para Ultramar (en 24 de octubre), no debía yo exponerme con repugnar la carta de Su Santidad, a que me retirasen, como era ya natural, dicha concesión, causando así un gravísimo daño a aquellas Iglesias y poniendo al Gobierno en un fuerte compromiso[... $]^{18}$

Apenas un mes más tarde, el 26 de noviembre de 1845, Gregorio XVI admitió la lista real de candidatos a ocupar las cuatro sedes ultramarinas vacantes

16 Ibid., pos. 285, fasc. 75. Ponencia estampa «Spagna. Varie istanze del Governo» de la Congregación de Asuntos Eclesiásticos Extraordinarios presentada en la sesión de 28 de noviembre de 1845 [numeradas sólo las primeras páginas a partir del f. 92r].

17 ROMA, ARCHIVO DE LA EMBAJADA DE ESPAÑA FRENTE A LA SANTA SEDE [=A.E.S.S], leg. 774. Carta del secretario de la Sagrada Congregación de los Asuntos Eclesiásticos Extraordinarios, el cardenal Vizzardelli, al enviado plenipotenciario de España, José Castillo y Ayensa, 27 de octubre de 1845.

$18 \mathrm{Ibid}$. Despacho $\mathrm{n}^{\circ} 268$ del enviado plenipotenciario de España, José Castillo y Ayensa, al primer secretario de Estado, Roma, 18 de marzo de 1846. 
con el compromiso del gobierno español de que «[...] esta presentación en nada alteraría el estado de las negociaciones pendientes, sin perjudicar los derechos y pretensiones de una u otra parte [...]» ${ }^{19}$ : José Aranguren, provincial de los agustinos descalzos en aquellas islas, fue presentado para el arzobispado de Manila; Romualdo Jiménez, obispo in partibus de Ruspa, para la diócesis de Cebú; Vicente Barreiro, agustino descalzo en las misiones de Filipinas, a la de Nueva Cáceres y Rafael Massoliver, provincial de los dominicos en aquellas isla, para la diócesis de Nueva Segovia, mientras que Francisco Fleix, canónigo de la catedral de Tarragona, lo fue para la diócesis de Puerto Rico ${ }^{20}$.

No había tenido aún lugar el consistorio donde ése último fue preconizado para la sede portorriqueña, cuando ya una real cédula de 14 de enero de 1846 ordenó a Castillo y Ayensa que iniciase las gestiones para su traslado de la sede puertorriquense a la diócesis de La Habana ${ }^{21}$. Las órdenes fueron recibidas en Roma apenas celebrado el consistorio de 19 de enero donde se presentaron los obispos para las mencionadas sedes filipinas y antillana, por lo que Ayensa no vio urgencia en la tramitación del expediente de traslado y sí más conveniente esperar la real cédula que presentase al candidato para la futura vacante de Puerto Rico ${ }^{22}$. El proceder del enviado contrastó con la opinión del agregado de la legación española en Roma, el clérigo Esteban Azpeitia, quien se hallaba en Madrid siguiendo los debates en torno al proyecto de dotación del clero. Azpeitia apremió al enviado plenipotenciario para que acelerase los trámites:

[...] Ya habrá V. leído en los periódicos el pastel que han hecho los cuatro canónicos de La Habana en cuanto al nombramiento de vicario. En vista de esto [...] creo que convendría muchísimo que la traslación de aquel [de Francisco Fleix] de Puerto Rico a La Habana se verificase inmediatamente $[\ldots]^{23}$

19 Ibid. Despacho no 212 del enviado plenipotenciario de España, José Caballero y Ayensa al primer secretario de Estado, Roma, 27 de noviembre de 1845; leg. 775. Despacho n 268 de José Castillo y Ayensa al primer secretario de Estado, Roma, 18 de marzo de 1846. Sobre las negociaciones del enviado extraordinario de España y Roma que concluyeron en la firma del Concordato de 1851 vid. José CASTILlO Y AYENSA, Historia crítica de las negociaciones con Roma desde la muerte del rey don Fernando VII, Imprenta Tejado, Madrid, 1859, 2 tomos.

20 A.E.S.S, leg. 775. Atti del concistoro segreto tenuto dalla Santità di Nostro Signore Papa Gregorio XVI, palacio apostólico vaticano, 19 de enero de 1846.

21 Ibid. Despacho n ${ }^{\circ} 242$ del enviado extraordinario al ministro de Gracia y Justicia. Roma, 28 de enero de 1846.

22 Ibidem.

23 Ibid., leg. 774. Esteban de Azpeitia a José Castillo y Ayensa, Madrid, 22 de enero de 1846. 
Un mes más tarde, ante la previsión de que el siguiente consistorio se celebrara en los días previos a la Semana Santa, Castillo y Ayensa insistía ante Azpeitia para que se le enviasen las cédulas de presentación para el obispado de Puerto Rico en un candidato que fuese conocido en Roma y sugiriendo en este destino el nombre del gobernador eclesiástico de Santiago de Cuba designado por el arzobispo:

[...] Se me ocurre una idea que pudiera servir para todos efectos y es la de que presenten a Delgado, si no le dan permiso para ejercer el vicariato de Cuba, en lo que veo hallan tantas dificultades. Yo creo que Delgado es aquí conocido y, por otra parte, se salía así del embarazo de su nombramiento, aunque de éste no puede prescindirse; pero ya veríamos como arreglarlo de otra manera más suave $[\ldots]^{24}$

La nueva crisis del gobierno de Madrid recomendó manejar con mucha prudencia la conveniencia de la propuesta y, efectivamente, pronto la idea fue abandonada. En una conversación que el agregado de la legación española Azpeitia mantuvo con el ministro de Gracia y Justicia, Arrazola, éste le confirmó la opinión desfavorable acerca de Delgado, a quien el ministro decía conocer desde años atrás. Esta reunión arroja luz sobre la resistencia del gobierno de Madrid a aceptarle como gobernador y que a la altura de marzo de 1846 aún no se había dado el pase a la carta de Gregorio XVI. Arrazola comentó al asesor Azpeitia que $\ll[\ldots]$ ha sabido muy reservadamente que la causa aún de las razones porque le protege el P. Cirilo es porque le suministra recursos en el estado de escasez que éste debe sufrir $[\ldots] \gg^{25}$. La negativa o las reticencias del gobierno en torno a la cuestión de la legitimidad del nombramiento, escondieron, en realidad, razones políticas: la ayuda económica de Delgado al arzobispo Alameda, cuyas simpatías carlistas eran conocidas. En este contexto, el asesor concluía las razones por que -a su juicio- convenía aceptar su presentación como vicario:

[...] la primera porque tal vez no se conoce ahí [en Roma] la insinuada excepción; lo $2^{\circ}$ porque este cargo es transitorio y muy inferior al obispado; $3^{\circ}$ porque la escandalosa desmoralización de aquel país y en la generalísima falta de quien sepa algo, ha sido acaso necesario escoger entre lo pésimo, lo menos pésimo $[\ldots]^{26}$

24 Ibid., leg. 775. El enviado plenipotenciario a Esteban Azpeitia [s.f.: ¿febrero? de 1846].

25 Ibid. Carta ${ }^{\circ} 6$ de Esteban Azpeitia a Castillo, Madrid, 13 de marzo de 1846. El dato cuya certeza pudiera ponerse en duda por ser fruto de una conversación privada queda confirmado por la documentación consultada y presentada por Santiago HigUERAS DE ANCOS, De la Facción a la monarquía..., op. cit.

26 Ibid. Carta n ${ }^{\circ} 3$ de Esteban Azpeitia a Castillo Ayensa, Madrid, 3 de marzo de 1846. 
El traslado de Fleix a la mitra de La Habana encontró una respuesta favorable en Roma, donde el secretario de Estado transmitió al enviado «[...] cuán grave [era] la amargura que el Santo Padre [ha] probado al advertir que la irregularidad de que era infecta la administración de la metropolitana de Cuba se [había] extendido de

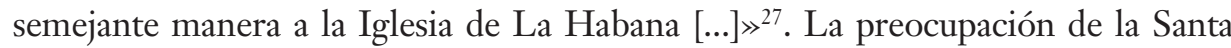
Sede aumentaba con los informes que el mismo vicario de La Habana enviaba periódicamente donde además de denunciar los problemas de la diócesis, retrataba a la sociedad habanera como a un «[...] pueblo entibiado en la fe y contaminado algún tanto con las falsas doctrinas de la perniciosa y audaz filosofía del siglo que ha pasado», donde la «falta de pastores que apacentaban las ovejas del Señor y un principio de relajación que se había ido extendiendo en algunos ministros del altar fueron motivo suficiente para causar los males que estamos deplorando todavía [...] $\gg^{28}$. En este contexto, se imponía la necesidad de preconizar a un obispo «hábil y celoso» ${ }^{29}$, una elección que efectivamente recayó en el candidato real, Francisco Fleix, quien unos meses antes recibió las facultades de administrar interinamente la diócesis ${ }^{30}$.

El 16 de abril de 1846 Fleix fue preconizado obispo de La Habana ${ }^{31}$ y su sucesor al frente del obispado de Puerto Rico, el sacerdote Francisco Puente, el 27 de julio, ya durante el pontificado del recién nombrado Pío IX ${ }^{32}$. Las causas de los vicarios -el de Santiago de Cuba y el de La Habana- se resolvieron poco tiempo después. Ante la insistencia de la Santa Sede en saber si Delgado había retornado al arzobispado a finales de julio una real orden del ministerio de Gracia y Justicia dio el pase a la carta de Gregorio XVI y dio órdenes para que Juan Pacheco regresase a la península y al capitán general para que «[...] [prestase] toda la ayuda de su autoridad en caso de necesidad a fin de que el prelado señor Delgado se encargue inmediatamente del nuevo gobierno de aquella metrópoli en su calidad de vicario

$27 \ll[. .$.$] Quanto grave sia l'amarezza che ha provato il Santo Padre nel rilevare, che la irregolarità di$ cui era infetta (?) l'amministrazione della metropolitana di Cuba si è in tal modo estesa (?) anche a quella della Chiesa di Havana [...]» (AA.EE.SS, Spagna I, pos. 286, fasc. 77. El cardenal secretario de Estado, el cardenal Lambruschini, al enviado extraordinario y ministro plenipotenciario de España, José Caballero y Ayensa, Quirinale, 7 de marzo de 1846, f. 115v).

28 Ibid., pos. 288, fasc. 78. Pedro Mendo al Papa, La Habana, 10 de abril de 1846, f. 98r.

29 Ibid., pos. 286, fasc. 77. El cardenal secretario de Estado, el cardenal Lambruschini, al enviado extraordinario y ministro plenipotenciario de España, José Caballero y Ayensa, Quirinale, 7 de marzo de 1846, f. 114r.

30 A.E.S.S, leg. 775. Rescripto pontificio, Roma, 4 de marzo de 1846.

31 Ibid. Atti del Concistoro pubblico e segreto tenuto dalla Santità di Nostro Signore Papa Gregorio XVI, palacio apostólico Vaticano, 16 de abril de 1846.

32 Ibid. Atti del Concistoro segreto tenuto dalla Santità de nostro Signore Papa Pío IV, palacio apostólico del Quirinale, 27 de julio de 1846. 
general del arzobispo, que ya del mismo que le fue conferida $[. ..] \gg^{33}$. Por su parte el vicario en sede vacante de La Habana continuó en el ejercicio de sus funciones hasta la llegada del obispo Fleix, quien lo absolvió de las irregularidades y lo asumió como su vicario, de forma que desde principios de diciembre de 1846 Mendo administró la diócesis con jurisdicción delegada ${ }^{34}$.

Estos dos episodios llevaron a la Iglesia en Cuba al borde de un cisma, cuyo final fue sólo posible después de que tanto Madrid como Roma transigieron en sus respectivas posiciones; sin embargo, todavía era preciso buscar que situaciones como las recién superadas no se volvieran a repetir, al tiempo que adoptar las medidas que remediasen el estado alarmante en que se hallaban las diócesis. Con este objetivo, se trató de darles un marco legislativo que regulase todas estas cuestiones y subsanase los efectos de la política desamortizadora y de venta de bienes de la Iglesia Iglesia ultramarina. Éstos serían dos de los cometidos del nuevo delegado pontificio en Madrid.

\section{LAS IGLESIAS ULTRAMARINAS EN LAS NEGOCIACIONES DEL CONCORDATO}

El 29 de mayo de 1847 llegó a Madrid Giovanni Brunelli con la misión de negociar y acordar con el gobierno español la forma de dar solución a los principales problemas que aquejaron a la Iglesia española y restablecer oficialmente las relaciones diplomáticas entre ambos estados con la firma de un Concordato. El delegado pontificio llegó investido de amplios poderes y con unas extensas y detalladas instrucciones de la Santa Sede sobre la respuesta que se buscaba dar a los problemas eclesiásticos de España y sobre los términos en que había de concretarse el arreglo del culto y clero. Los asuntos eclesiásticos de las «provincias ultramarinas» se limitaban a sólo dos puntos ${ }^{35}$. En el artículo 28, las instrucciones

33 «[...] presti l'aiuto di una sua autorità in caso di bisogno, affinché il prelodato signor Delgado s'incarichi immediatamente di nuovo del governo di quella metropolitana, nella sua qualifica di vicario generale del arcivescovo, che già dal medesimo gli fu conferita [...]» (ibid., Minuta de Castillo al cardenal secretario de Estado Gizzi, palacio real de España, 15 de agosto de 1846); ibid., despacho n $^{\circ} 326$ de Castillo y Ayensa al primer secretario de Estado. Roma, 18 de agosto de 1846.

34 AA.EE.SS, Spagna I, pos. 332, fasc. 93. Carta de Pedro Mendo [sin destinatario: ¿Pío IX?], Madrid, 27 de enero de 1849 , ff. 42r-44r.

35 «Istruzione per Mgr. D. Giovanni Brunelli, arcivescovo di Tessalonica, che dalla Santità di N. S. viene inviato colla qualifica di suo delegato apostolico a Madrid (22 abr. 1847)» (F. DÍAZ DE CERIO y M. F. NÚÑEZ Y MUÑOZ, Instrucciones secretas a los nuncios de España en el siglo XIX (18471907), Editrice Pontificia Università Gregoriana, Roma, 1989, pp. 17-31). 
comisionaron a Brunelli que tratase con el gobierno sobre la «[...] subsanación/ remedio de los actos realizados en las precedentes turbulencias y que sean absolutamente o probablemente nulos por defecto de canónica jurisdicción[...] $\gg^{36}$, refiriéndose a la desamortización y exclaustración de los regulares que se había implementado durante gobierno de Espartero, una de cuyas consecuencias fue la práctica desaparición de los conventos en las Antillas españolas, a excepción de la diócesis de La Habana donde consiguieron sobrevivir unos pocos ${ }^{37}$. En relación a los regulares, el punto 33 de las instrucciones encomendó al delegado pontificio:

[...] poner atención para que puedan prosperar siempre más aquellos conventos, que se han conservado en las Iglesias y Misiones de Ultramar. Es más por aquello que se refiere al menos a la diócesis de La Habana se podría intentar desde ahora el restablecimiento permanente de alguno de los conventos allí suprimidos; procurando que el gobierno los considere como comunidades para las misiones. Se ha dicho al menos en La Habana, porque no se sabe cuál es el estado en que se encuentran las cosas regulares en aquellas lejanas regiones conservadas $[\ldots]^{38}$

El restablecimiento de las órdenes religiosas en los territorios de ultramar fue un objetivo de primer orden para Roma desde el comienzo de las negociaciones con España. En el caso de Cuba, para solucionar la falta de legítimos superiores -bien por razón de muerte o renuncia- de las comunidades supervivientes, en un primer momento la Santa Sede nombró comisarios apostólicos de las comunidades extinguidas. La medida resultó contraproducente y poco efectiva: si, por un lado, atentó contra el contenido de la Bula Inter Graviores de 15 de noviembre de 1804, que estableció que la residencia de los superiores de las órdenes religiosas debía radicar en la península, lo cual dio a la Corona una

$36 \ll[\ldots]$ sanazione degli atti fatti nelle precedenti turbolenze e che siano assolutamente o probabilmente nulli per difetto di canonica giurisdizione [...]» (ibid., p. 26).

37 Sobre la desamortización en Cuba y Puerto Rico: Juan Bosco Amores Carredano, La desamortización de bienes de regulares en Cuba, siglo XIX, en Luis E. GONZÁLEZ VALES (coord.), Actas del XIII Congreso Internacional de Historia del Derecho Indiano, Historiador Oficial de Puerto Rico, San Juan, 2003, vol. 2, pp. 91-106; Rigoberto SEGREO RICARDO, Conventos y secularización en el siglo XIX cubano, Ciencias Sociales, La Habana, 1998; Almudena HeRNÁNDEZ RUIGÓMEZ, La desamortización en Puerto Rico, Cultura Hispánica/Instituto de Cooperación de Iberoamérica, Madrid, 1987.

$38 \ll[. .$.$] aver cura perché possano sempre più prosperare quei conventi, che si sono conservati per le$ Chiese e Missioni di oltremare. Anzi perciò che riguarda almeno la diocesi di Avana potrebbe fine da ora tentarsi di ripristinare stabilmente qualcuno de conventi ivi pure soppressi; procurando che il governo li riguardi come comunità per le missioni. Si è detto almeno nell'Avana, poiché non si sa in quale stato si trovino le cose dei regolari nel rimanente di quelle lontani regioni $[. .]$. (DÍAZ DE CERIO y NúÑEZ Y MUÑOZ, Instrucciones secretas..., op. cit., p. 28). 
mayor capacidad de control y de injerencia sobre las mismas; por otro parte, el hecho de que los nuevos comisarios apostólicos residiesen en su mayor parte en Roma fue un obstáculo insalvable para la comunicación de estos superiores con sus subordinados, la distancia y las difíciles comunicaciones entre la Santa Sede y Cuba -unidas a la legislación española-impidieron que los religiosos les reconocieran como superiores. La solución llegó del propio obispo de La Habana, Fleix y Solans, cuando solicitó a la Santa Sede la concesión de la delegación apostólica de ejercer la misma jurisdicción que había correspondido a los superiores sobre los regulares de ambos sexos hasta el momento de la medida desamortizadora (Real Orden de 22 de junio de 1841). Las facultades delegadas le fueron concedidas por un bienio por el rescripto de la Congregación de Asuntos Eclesiásticos Extraordinarios el 15 de septiembre de $1847^{39}$.

Desde su llegada a Madrid, una de las cuestiones en las que trabajó el nuncio fue la de buscar una solución al estado de abandono en que se hallaron la Iglesia en las islas y el restablecimiento y fomento de las órdenes regulares. Según el mismo Brunelli, todo ello lo hizo:

[...] con muchísima cautela y prudencia, consciente que los gobiernos españoles de cualquier tiempo y partido, apoyados en la delegación apostólica acordada, como se pretende, por Alejandro VI y otros Pontífices a los Reyes Católicos en relación a las Iglesias de Ultramar, estuvieron siempre interesados en evitar y excluir cualquier intervención de los nuncios en las mismas $[. . .]^{40}$

Las gestiones del nuncio en este sentido fueron lentas y dieron escaso resultado hasta que un suceso inesperado vino a crear las circunstancias propicias para que el gobierno aceptase a tratar con él la cuestión de las órdenes regulares en ultramar. El episodio en cuestión fue el intento de invasión de Cuba por parte del general Narciso López en 1849, sospechoso de haber sido

39 VATiCANO, ARCHIVIO SEgReto VATICANO [=ASV], Archivio della Nunziatura di Madrid [=Arch. Nunz. Madrid], scatola 309, Tit. IV, Rub. 12a ,ff. 554r-v. En 1852 estas facultades le fueron prorrogadas por un bienio más (ibid., f. 561r. El cardenal secretario de Estado a Brunelli, nuncio apostólico en Madrid, Roma, 3 de julio de 1852).

$40 \ll[\ldots]$ con moltissima cautela e prudenza, essendomi ben noto che i governi spagnoli di qualunque tempo e partito, appoggiati alla permanente delegazione apostolica accordata, come si pretende da Alessandro VI e da altri pontefici ai re cattolici in ordine alle chiese di Oltremare, furono sempre intesi ad evitare ed escludere ogni intervenzione dei nunzi in quanto si riferisce alle medesime [...]» (AA.EE.SS, Spagna II, pos. 418, fasc. 122, 26r-29v. Despacho n ${ }^{\circ} 527$ del nuncio apostólico al cardenal secretario de Estado, Madrid, 1 de septiembre de 1852) [La cursiva en el cuerpo de texto es nuestra]. 
auspiciado por el gobierno de Washington, que puso en evidencia hasta qué punto la sombra de la amenaza extranjera que se cernía sobre las islas era real: en el gobierno de Madrid estaba aún vivo el recuerdo de la independencia de la América continental española y veía concretarse la posibilidad de perder la que era conocida como Perla de las Antillas, donde, por otra parte, un sector de la población buscaba la anexión a los Estados Unidos.

Los vínculos de la isla con su vecino geográfico no fueron un secreto para el gobierno y las autoridades coloniales; sin embargo, a raíz de los últimos sucesos, el gobierno debió ver con mayor preocupación el hecho de que algunas familias cubanas con recursos enviasen a sus hijos a estudiar a los Estados Unidos, donde encontraron una formación más acorde a los tiempos que corrían y a las actividades que estaban llamados a desempeñar en los negocios familiares. Durante su estancia muchos terminaron por entrar en contacto e imbuirse de los «errores contra la pureza del dogma» ${ }^{41}$. Igualmente no fue vista con menor preocupación el hecho de que algunas parejas pasasen a los Estados Unidos a contraer matrimonio $^{42}$. Todo ello suponía una posibilidad real de contagio de ideas y de hábitos que después, al regreso, eran difundidas en la isla. Se imponía poner cuantos remedios estuvieran al alcance para frenar estos contactos.

Tras el intento de invasión de López, Madrid no sólo reforzó militarmente la isla, sino que comenzó a considerar que esto no era suficiente para garantizar su soberanía, que también debía garantizarse la fidelidad de la población a la Corona y combatir todo tipo de corrupción; una idea que el mismo nuncio se encargó de alimentar en sus reuniones «amistosas» con los ministros, donde les persuadió:

[...] que el verdadero y eficaz medio de reafirmar la pacífica sujeción y obediencia a la dominación española de los habitantes de las Antillas era aquel de avivar y difundir los principios religiosos y de moralidad y que este fin, no pudiendo recaer sobre

41 MADRID, ARCHIVO HISTÓRICO NACIONAL [=AHN], Ultramar [=Ultr], 1707, exp. 18, doc. 12. Antonio María Claret a Isabel II, Manzanillo, 24 de mayo de 1852.

42 Se dieron casos de parejas en las que existía algún impedimento canónico para contraer matrimonio que viajaron a los Estados Unidos para hacerlo delante de obispos quienes tenían delegadas la facultad apostólica de dispensar de estos impedimentos (ASV, Arch. Nunz. Madrid, scatola 332. El obispo de La Habana a Giovanni Brunelli, La Habana, 1 de agosto de 1847, ff. 796r-797v). El 18 de septiembre de 1848 el embajador en Roma, Castillo y Ayensa envió al obispo de La Habana un pliego que contenía cinco rescriptos pontificios, entre ellos, la facultad de dispensar conforme al Breve de 27 de mayo de 1770 de Clemente XIV «ad septennium» (ibid., scatola 323, Despacho $\mathrm{n}^{\circ} 79301$ del secretario de Estado Santucci al delegado apostólico en Madrid, Roma, 22 de enero de 1848, ff. 15r-16r. [subrayado en el original]). 
el ignorante, inerte, escandaloso y escasísimo clero indígena, era indispensable el restablecimiento de las comunidades religiosas, sujetándolas a la plena observancia de sus reglas e integrándole por sujetos animados por el celo y espíritu de vocación, edificantes e instruidos en la península $[\ldots]^{43}$

Los argumentos de Brunelli no demostraban una realidad ajena a los ministros y sus palabras llovían en terreno fecundo: el gobierno, que estuvo siempre informado de los problemas de la Iglesia cubana, impulsó desde 1842 un expediente para dotar a la isla de un arreglo de culto y clero. En este sentido, las instrucciones del nuncio y sus gestiones se complementaron perfectamente con los argumentos y trabajos que ya se estaban haciendo por parte de las autoridades eclesiásticas y políticas de la isla.

Desde junio de 1845 una Junta de fuero mixto trabajaba en el conocido como arreglo del culto y clero de Cuba, un expediente que quedó vinculado a la cuestión de la abolición del diezmo y su subrogación o sustitución por otra contribución promovida por la Junta de de la Fomento, de Agricultura y Comercio de La Habana y a la del restablecimiento de los regulares. Desde el punto de vista que nos ocupa, la junta constató -entre otras cuestiones- que la isla carecía de un clero suficiente para atender las necesidades del pasto espiritual de la población, que el existente estaba mal dotado y escasamente formado ${ }^{44}$. Estas informaciones fueron

$43 \ll[\ldots]$ che il vero ed efficace mezzo di riaffermare gli abitanti delle Antille nella pacifica soggezione ed obbedienza alla dominazione spagnola era quello di ravvivarvi e diffondervi i principi di religione e moralità e che a questo fine, non potendo affatto contarsi sull'ignorante, inerte, scandaloso, scarsissimo clero indigeno era indispensabile il ristabilimento delle comunità religiose, assoggettandole alla piena osservanza delle loro regole e componendole di soggetti animati da zelo e spirito di vocazione, edificanti, ed istruiti nella penisola [...]» (AA.EE.SS, Spagna II, pos. 418, fasc. 122. Despacho $\mathrm{n}^{\circ} 527$ del nuncio apostólico al cardenal secretario de Estado Madrid, 1 de septiembre de 1852 , ff. $26 \mathrm{r}-29 \mathrm{v})$.

44 El artículo 9 del decreto de 9 de septiembre de 1842 que puso fin al régimen de exenciones al diezmo con las que desde la última década del siglo XVIII la Corona había privilegiado a los principales productos agrícolas de la isla con el objetivo de favorecer su producción, estableció la creación de una junta especial en La Habana, cuyo objetivo era «[fijar y proponer] las dotaciones que estime justas, prudentes y oportunas para todos los individuos de las diversas clases que componen el clero de ambas diócesis y para que los gastos de fábrica, procurando que ni respecto de unos, ni de otros se incurran en extremos que ofendan a la equidad». La Junta estuvo constituida por el capitán general Cuba en calidad de presidente, del superintendente delegado de Hacienda, de dos canónigos - una de la catedral de Santiago de Cuba y otro de la de La Habana-, un cura párroco de cada diócesis -elegidos por sus respectivos obispos-, el regente de la audiencia pretorial de La Habana, el contador mayor decano del Tribunal de Cuentas, el Contador general de Ejército y Hacienda, del fiscal de Hacienda y, finalmente, del contador de Diezmos (AHN, Ultr, 692, exp. 3, doc. 25. Madrid, 9 de septiembre de 1842). Sobre el régimen del diezmo ver: Consolación FERNÁNDEZ MElléN, Iglesia y poder en la Habana. Juan Fosé Díaz de Espada, un obispo ilustrado 
confirmadas por los obispos de la isla. En 1848 Francisco Fléix se refería al arreglo del culto y clero como de un «eficaz remedio a los males de la Iglesia en Cuba, que indudablemente ha sido y será el primer eslabón de la cadena que la une a la madre patria» ${ }^{45}$, desgranaba cuáles eran esos males y proponía las soluciones que debían adoptarse. El retrato del estado religioso de la isla que el obispo de La Habana dibujó no podía menos que alertar a sus destinatarios: la escasez de sacerdotes y la insuficiente formación así como el ruinoso y escaso número de iglesias, entre otros defectos, habían contribuido a extender la «indiferencia» y el «idiotismo», especialmente en los campos:

[...] es la verdad: que si la Isla ha dado pasos de gigante en la carrera de la prosperidad material, también ha retrocedido no poco en el camino abierto por la Religión y la Moral. Mirada por este lado, su aspecto es tan poco lisonjero, y acaso tan desgarrador, que exige imperiosamente, en mi juicio, la más pronta aplicación de cuantos medios puedan conducir a la cura de unos males, que progresando producirán, andando los días, los frutos que recogieron siempre los pueblos mal aventurados, que se burlaron y se mofaron de los dogmas conservadores de la moral consoladora de los hombres, de aquella moral que les impide morir a fuerza de odios y de desórdenes y les hace vivir tranquilos, bien subordinados a la autoridad que Dios ordenó $[\ldots]^{46}$

Apenas unos meses más tarde, desde la capital del reino, el arzobispo de Santiago de Cuba fray Cirilo de Alameda describía y confirmaba una situación similar para su arzobispado en un informe que se ocupaba especialmente de argumentar la necesidad de reabrir los conventos por los beneficios que de ellos se derivaban en el orden religioso (confesión, púlpito, misiones), educativo, asistencial... y político: «[...] La educación moral y científica ganaría mucho, las costumbres mejorarían y las castas que pueblan las haciendas del campo depondrían su feroz rudeza, alejándose así el fundado temor de que se aprovechen de ella los enemigos de tan preciosa posesión española $[\ldots] \gg^{47}$.

(1800-1832), Bilbao, Universidad del País Vasco, 2014, pp. 125-161; Ana IRISARRI AGUIRRE, El oriente cubano durante el gobierno del obispo foaquín de Osés y Alzúa (1790-1823), Eunsa, Pamplona, 2003, pp. 125-136; Rigoberto SEgREO RICARDO, De Compostela a Espada. Vicisitudes de la Iglesia Católica en Cuba, Ciencias Sociales, La Habana, 2000, pp. 83-115.

45 AHN, Ultr., 692, exp. 6, doc. 9. El obispo de La Habana Francisco Fleix al Secretario de Estado y del Despacho Universal de Hacienda, La Habana, 10 de julio de 1848.

46 Ibidem.

47 Ibid., doc. 11. El arzobispo de Cuba fray Cirilo Alameda al secretario de Estado y del Despacho de Hacienda, Madrid, 8 de noviembre de 1848. 
Todos estos informes dirigidos al gobierno coincidieron en describir el mismo estado decadente de la religión, en dibujar una sociedad dominada por el indiferentismo religioso, la relajación de las costumbres y el individualismo y en alertar sobre las consecuencias no sólo religiosas, sino también políticas que derivan en esta situación, máxime en una isla donde la población de color superaba a la blanca. El ya conocido temor a una posible sublevación esclava, ejemplos de las cuales se hallaban en la memoria colectiva ${ }^{48}$ :

[...] este país, más necesitado acaso por su especial organización que otro alguno, del amparo poderoso que presta a todos en sus violentas crisis la acción salvadora del cristianismo; porque este pueblo tan poco parecido a los demás y compuesto, como lo está, de razas tan diversas en su color, en sus formas, en sus propensiones y educación, apenas puede haber entre ellas más lazos de íntima unión y fraternidad, que el que echa sobre todos la religión, que nunca se cansará, cuando esté mejor servida de predicar y de inculcar encarecidísimamente la resignación a los esclavos, la compasión a los señores y a todos la obediencia cordial y la fidelidad sincerísima que deben a su soberana excelsa $[\ldots]^{49}$

Todas estas razones trabajaron a favor del arreglo del culto y clero y del restablecimiento de los religiosos en Cuba, al tiempo que allanaron el camino a la labor de Brunelli, quien no sólo se limitó a favorecer la causa de los religiosos, como le fue ordenado en las instrucciones, sino que buscó un compromiso del gobierno y que éste quedase recogido en el texto concordatorio que estaba ajustando con el gobierno español.

En el verano de 1850 comenzaron oficialmente las negociaciones del Concordato entre el nuncio y el ministro de Estado, el moderado Pedro José Pidal, que trabajaron sobre la base de una memoria que sobre el arreglo del culto y clero en la península elaboró en 1848 una Junta mixta, integrada por vocales elegidos por el gobierno y el nuncio. En este documento quedó claro cuál sería la postura del gobierno respecto a las negociaciones de los asuntos de la Iglesias de Ultramar. Siguiendo las directrices del gobierno, la Junta declaró «no deber tratarse en el arreglo de las Iglesias de América, ya porque la desorganización introducida en las Iglesias de la península apenas ha alcanzado allí, ya también porque todo lo que

48 Sobre la instrumentalización política que se hizo del miedo a una posible revolución de esclavos ver: $M^{a}$ Dolores GONZÁLEZ-RIPOLL, Consuelo NARANJO OROVIO y Ada FERRER et al., El rumor de Haití en Cuba: temor, raza y rebeldía, 1789-1844, CSIC, Madrid, 2005.

49 AHN, Ultr., 1707, exp. 15, doc. 11. El capitán general José de la Concha al ministro de Gracia y Justicia, La Habana, 15 de febrero de 1851. 
afecta a aquellos países debe tratarse de una manera especial» ${ }^{50}$. Sólo el artículo 8 de la memoria se refirió específicamente a la iglesia ultramar. Su contenido recogía que no se haría más cambio «por ahora» que el declarar la iglesia de Puerto Rico como sufragánea del arzobispado de Santiago de Cuba. Respecto al «por ahora», Brunelli se felicitó años más tarde ante la Congregación de Asuntos Eclesiásticos Extraordinarios, porque su inclusión había sido fruto de las insinuaciones que él mismo había hecho «[...] a los vocales designados por él [...], con lo cual pretendió dejar abierto hueco a la Santa Sede para que a su debido tiempo promoviera las oportunas negociaciones para las reformas que tanto necesitan aquellas iglesias $[\ldots] \gg^{51}$.

A pesar de ello Brunelli no perdió ocasión de tratar los asuntos de la Iglesia ultramarina siempre que tuvo la oportunidad. En una conversación con el ministro Pidal, éste le habló de la gran firmeza del gobierno en no dar ningún paso que atentase contra las regalías, el patronato «especial» y la delegación apostólica:

[...] que durante casi cinco siglos poseían los reyes católicos en las Indias por bulas pontificias y en virtud de las cuales pueden con plena y libre autoridad disponer todo aquello que les parezca más útil y conveniente a cerca de la conversión de los infieles, el progreso de las misiones y también el gobierno espiritual de los religiosos $\mathrm{y}$ de otros eclesiásticos de las mismas [misiones] $[\ldots]^{52}$

En opinión del ministro:

[...] El gobierno de S.M. no habría podido asumir en el concordato cualquier obligación, particularmente respecto a las Filipinas, sin perjudicar no mucho las referidas prerrogativas y extraordinarias atribuciones de la Corona; y, en este caso, habría comprometido incluso su existencia [la del Gobierno], provocando la hosti-

50 «Memoria justificativa del proyecto» en Juan PÉREZ ALHAMA, La Iglesia y el Estado español, Instituto de Estudios Políticos, Madrid, 1967, p. 526.

$51 \ll[. .$.$] i vocali da me nominati insistettero a mia insinuazione ed a stento poterono conseguire che$ vi si aggiungessero le parole per ora, con cui io ebbi in vista di lasciare aperto l'adito alla Santa Sede di promuovere a suo tempo le opportune negoziazioni per le riforme, di cui tanto abbisognano quelle chiese [...]» (AA.EE.SS, Spagna I, pos. 361, fasc. 105, doc. 52. Despacho en clave $n^{\circ} 352$ de Brunelli [a la Congregación de Asuntos Eclesiásticos Extraordinarios], Madrid, 13 de marzo de 1851, f. $99 \mathrm{v})$.

$52 \ll[. .$.$] di cui per più bolle pontificie sono in possesso da circa cinque secoli i re cattolici rispetto alle$ Indie ed in forza delle quali, possono con piena, e libera autorità disporre ciò che sembri loro più utile e conveniente circa la conversione degli infedeli, il progresso delle missioni, ed il governo anche spirituale dei religiosi e di altri ecclesiastici addetti alle medesime [...]» (ibid., f. 193). 
lidad de todos los partidos, sin excluir al más moderado, el cual, siendo propenso a concesiones liberales en política, asimismo es un sostenedor tenaz de las regalías, siempre nocivas a la libertad de la Iglesia $[\ldots]^{53}$

Estaba claro que el gobierno se resistiría a permitir cualquier intervención que pudiera sentar un precedente para una futura injerencia de la Santa Sede o que le reconociese cualquier capacidad de intervención sobre el gobierno de la Iglesia ultramarina (con la consiguiente disminución de los derechos de patronato); aunque esto no impidió que el ministro - previa consulta a las Cortes- cediese a incluir en el concordato la disposición del gobierno a mejorar los colegios de misiones para ultramar, contentando así al nuncio pontificio en una cuestión que - en realidad-Madrid estaba interesado por igual desde un punto de vista no sólo religioso, sino también político ${ }^{54}$.

Según reconocerá el propio Brunelli, si las negociaciones del articulado del proyecto de concordato fueron «difíciles y penosas», la de los artículos 29 y 30 que se refirieron a la cuestión del clero regular masculino y femenino « $[. .$.$] se$ pueden decir las más embarazosas y molestas [...] $\gg^{55} \mathrm{y}$, particularmente, en lo tocante a las comunidades religiosas de Cuba y Puerto Rico. A pesar del interés manifestado en ellas por el gobierno, a duras penas el artículo 29 del texto convino en el establecimiento de casas y corporaciones religiosas en la península:

Art. 29. A fin de que en toda la Península haya número suficiente de ministros y operarios evangélicos de quienes puedan valerse los Prelados para hacer misiones en los pueblos de su Diócesis, auxiliar a los Párrocos, asistir a los enfermos, y para otras obras de caridad, y utilidad pública, el Gobierno de S.M., que se propone mejorar oportunamente los colegios de Misiones para Ultramar, tomará desde luego las disposiciones convenientes para que se establezcan donde sean necesario, oyendo previamente a

$53 \ll[\ldots]$ il governo di S.M. non avrebbe potuto assumere nel concordato una obbligazione qualsiasi a riguardo particolarmente delle Filippine senza pregiudicare alcun tanto alle riferite prerogative e straordinarie attribuzioni della Corona; ed in questo caso avrebbe perfino compromesso la sua esistenza, provocando l'ostilità di tutti i partiti, non escluso il più moderato, il quale come è propenso alle concessioni liberali in politica, così è tenace sostenitore delle regalie sempre nocive alla libertà della Chiesa [...]» (ibid., ff. 193-194).

54 Sobre la importancia económica de Cuba para la metrópoli: J. CAYUELA FERNÁNDEZ, Babía de Ultramar. España y Cuba en el siglo XIX. El control de las relaciones coloniales, Siglo XXI, Madrid, 1993; Antonio SANTAMaría García y Alejandro García Álvarez, Economía y colonia. La economía cubana y la relación con España, 1765-1902, CSIC-Instituto de Historia, Madrid, 2004.

$55 \ll[\ldots]$ possono dirsi dei più imbarazzanti e molesti [...]» (AA.EE.SS, Spagna I, pos. 361, fasc. 101, doc. 11. «Progetto di Concordato mandato da Monsignor Brunelli, arcivescovo di Tessalonica e Nunzio Apostolico nel Regno di Spagna unitamente alle sue osservazioni» en «Stampa che servi per la sessione dei 13 ottobre 1850», f. 183). 
los Prelados diocesanos, Casas y Congregaciones religiosas de San Vicente de Paúl, San Felipe Neri y otra Orden de las aprobadas por la Santa Sede, las cuales servirán al propio tiempo de lugares de retiro para los eclesiásticos, para hacer ejercicios espirituales y para otros usos piadosos ${ }^{56}$.

De esta forma, el gobierno se comprometió de algún modo a su cumplimiento ante la Nación, por cuanto el concordato, una vez firmado, pasó a ser ley de Estado. Brunelli pensaba que «[...] presentándose la ocasión, esta alusión pasajera no sería inútil de cara a conseguir los justos deseos de la Santa Sede en orden a las comunidades religiosas de los dominios españoles de Asia y América [...] ${ }^{57}$.

\section{Ultimas INTENTOS DE EXTENDER EL CONCORDATO A LA IGLESIA DE ULTRAMAR}

Todavía antes de la firma del concordato, se trató de introducir algunas modificaciones al proyecto, entre otras, una referida a las iglesias de Ultramar. La firma del concordato fue una carrera a contrarreloj. Ante la crisis ministerial del tercer gabinete de Narváez, la subsiguiente previsión de que las nuevas Cortes se abriesen en diciembre de 1850 (finalmente convocadas para el 31 de octubre de ese año) y la posibilidad de que en la nueva legislatura al frente del gobierno se produjese un cambio de ministros que obstaculizase el proyecto de concordato y que quisiese renegociar los términos del mismo, el ministro de Estado Pidal apremió a Brunelli para que acelerase los trámites de la firma. Entre las razones del ministro no pesó menos su interés en figurar en la primera línea de las negociaciones y de la firma del concordato, «[...] atribuyéndose exclusivamente, no sin razón, el mérito y estando íntimamente convencido de haber realizado el más grande servicio a la Iglesia y al Estado [...] $\gg^{58}$. Así el nuncio fue enviando a Roma el proyecto de concordato con sus observaciones por partes a

56 Valladolid, ARChivo General de SimanCas (=AGS), Patronato, leg. 40, doc. 10, Concordato de 26 de marzo de 1851, f. 155r. [La cursiva es nuestra].

$57 \ll[. .$.$] all'opportunità questo cenno passeggero non sarà inutile all'adempimento dei giusti desideri$ della S. Sede in ordine alle Comunità Religiose dei Domini Spagnoli in Asia, ed America [...]» (AA.EE.SS, Spagna II, pos. 361, fasc. 101, doc. 11. «Progetto di Concordato mandato da Monsignor Brunelli», f. 194).

$58 \ll[\ldots]$ attribuendosene esclusivamente, e non senza ragione, il merito ed essendo intimamente convinto di aver reso il più grande servizio alla Chiesa di Spagna e insieme allo Stato [...]» (ibid., pos. 361, fasc. 101, doc. 14a. Despacho en $n^{\circ} 319$ en clave de Brunelli al cardenal secretario de Estado, ff. 22r-v). 
fin de que la Congregación de Asuntos Eclesiásticos Extraordinarios las revisase y aprobase ${ }^{59}$.

Una de las cuestiones sobre las que llamó la atención el dicasterio fue que ninguno de los artículos se refería a la Iglesia de Ultramar; un vacío éste que se hizo muy significativo cuando examinó el artículo 20 relativo a los vicarios generales en sede vacante, cuya nómina había sido ya objeto de tensión entre Madrid y la Santa Sede ${ }^{60}$. Episodios como los del arzobispado de Cuba y de La Habana, unidos a otros casos similares que se produjeron en las diócesis de la península durante la ruptura de las relaciones oficiales entre ambos Estados, explican el interés de La Congregación de Asuntos Eclesiásticos, que, sin embargo, no ignoró las dificultades de introducir un artículo que explícitamente se refiriese al abuso en la nómina de los vicarios en las iglesias ultramarinas, las cuales muchas veces eran resultado de la intervención de la autoridad civil del territorio. La Congregación consideró

[...] que el único remedio de combatirlo [era] añadir, si no existiese ya en el mismo concordato, un artículo con el cual se extendiesen genéricamente las cosas acordadas a las indicadas diócesis [ultramarinas], a excepción de las circunscripciones de las diócesis y cualquier otra disposición que fuese conveniente excluir $[\ldots]^{61}$

A lo largo del mes de diciembre -habiéndose producido los primeros cambios de ministros y cuando aún la crisis ministerial no había pasado- el nuncio Brunelli y el ministro de Estado mantuvieron diversas conferencias para tratar de los cambios propuestos por la Congregación, en las cuales el nuncio no puedo

59 Vicente CÁRCEL OrTí, El nuncio Brunelli y el Concordato de 1851, en Anales Valentinos, 1 (1975), pp. 79-198 y 309-377.

60 «Art. 20. En Sede vacante, el Cabildo de la iglesia metropolitana o sufragánea en el término marcado y con arreglo a lo que previene el sagrado Concilio de Trento, nombrará un solo Vicario capitular, en cuya persona se refundirá toda la potestad ordinaria del Cabildo sin reserva o limitación alguna por parte de él, y sin que pueda revocar el nombramiento una vez hecho ni hacer otro nuevo; quedando por consiguiente enteramente abolido todo privilegio, uso o costumbre de administrar en cuerpo, de nombrar más de un Vicario o cualquiera otro que bajo cualquier concepto sea contrario a los dispuesto por los sagrados cánones» (AGS, Patronato, leg. 40, doc. 10. Concordato de 26 de marzo de 1851, ff. 153r-v.).

$61 \ll[\ldots]$ che l'unico rimedio per combatterlo è quello di aggiungere, qualora non vi fosse nel concordato medesimo, un articolo col quale genericamente si estendono alle indicate chiese le cose convenute, ad eccezione della circoscrizione delle diocesi, e di qualche altra disposizione che meritasse di essere eccettuata (...)» (AA.EE.SS, Spagna II, pos. 361, fasc. 101, doc. 12. Sesión nº 296 de la Congregación de Asuntos Eclesiásticos Extraordinarios sobre los artículos acordados entre el nuncio y el gobierno de España, palacio del cardenal Macchi, 13 de octubre de 1850, ff. 11r$12 \mathrm{v})$. [La cursiva es nuestra]. 
siquiera llegar a tratar el punto de a las iglesias ultramarinas ${ }^{62}$. Entretanto, la crisis del gabinete de Pidal dio paso a mediados de enero a un nuevo gobierno a cuya cabeza estaba Bravo Murillo como presidente del Consejo y Bertrán de Lis como ministro de Estado. Éste, siendo ministro de Hacienda, había decretado en 1848 la venta de los bienes del clero que aún no habían sido enajenados y además se había convertido en un conocido comprador de los mencionados bienes. Junto a ellos el ministerio de Gracia y Justicia quedó en manos de Romero González, quien había sido miembro de la Junta Mixta que había declarado que la Iglesia ultramarina quedaría fuera de las negociaciones. La composición del nuevo gabinete no podía generar peores expectativas de cara a la futura firma del concordato, hasta el punto que el nuncio llegó a pensar en la posibilidad de que quisiesen volver sobre el articulado ${ }^{63}$.

El nuevo gabinete sostuvo con tenacidad sus posiciones y se negó a aceptar cualquier argumento que cuestionase las prerrogativas del patronato real. Esta actitud chocó con la férrea posición de la Congregación de Asuntos Eclesiásticos Extraordinarios, que sin embargo se mostró conforme en que no pudiendo hacerse la extensión a todo el texto íntegro del concordato, al menos sí al mencionado artículo 20, sobre los vicariatos en sede vacante, bajo condición de que si el gobierno no aceptaba este punto, tampoco la Santa Sede reconocería las modificaciones pretendidas por Madrid, particularmente en cuestiones económicas ${ }^{64}$. En contra de su opinión y vencido por las presiones de la Congregación, Brunelli trató en dos ocasiones de cumplir las órdenes de la Congregación, de las cuales sólo pudo obtener una nota diplomática del gobierno. El 13 de marzo el secretario de Estado Bertrán de Lis, tras reconocer la importancia de lo pretendido por la Santa Sede y la necesidad de estudiar lo propuesto en relación al artículo 20, mostraba la disposición del gobierno a «acoger» sus indicaciones y se reservaba «resolver, de acuerdo con la Santa Sede, sobre materia tan grave cuando tenga los datos y noticias necesarios al efecto» ${ }^{65}$.

62 ASv, Arch. Nunz. Madrid, scatola 323, tit. x, parte 4a, rúbrica 2a , parte $1^{\text {a }}$. Despacho $\mathrm{n}^{\mathrm{o}} 341$ del nuncio al secretario di Estado, 13 de enero de 1851, ff. 423r-424v.

$63 \mathrm{Ibid}$. Despacho $\mathrm{n}^{\circ} 342$ de Brunelli al cardenal secretario de Estado, enero 1851, ff. 438r-439r.

$64 \ll[\ldots]$ qualora il governo non vi aderisse, intendeva che neppur ci avessi usato della sua annuenza in ordine alla vendita e conversione in titoli del 3 per \% dei pochi beni di pertinenza delle confraternite, santuari ed altri luoghi pii [...]» (ASV, Arch. Nunz. Madrid, scatola 323, tit. X, parte 4a rúbrica $2^{\mathrm{a}}$, parte $2^{\mathrm{a}}$. Despacho $\mathrm{n}^{\mathrm{o}} 361$ de Brunelli al cardenal secretario de Estado, 27 de marzo de 1851, f. 677r).

65 Ibid. El secretario de Estado, Manuel Bertrán de Lis, al nuncio apostólico, palacio, 13 de marzo de 1851 , f. 683 r. 
A estas alturas, Brunelli, que ya estaba convencido de la imposibilidad de conseguir mayores concesiones respecto a la Iglesia de Ultramar, escribió un despacho a la Congregación donde tras un extenso un análisis, que demuestra un profundo conocimiento de la realidad política y la diplomacia española, concluye con un clarividente diagnóstico de la raíz de los males de la Iglesia indiana y las causas que habían contribuido a perpetuarlo:

[...] Tengo que declarar antes de nada que es superior a toda expresión el celo y tenacidad del gobierno español el sostener por medio del así llamado Consejo de Indias primero y ahora por el Ministerio de Gracia y Justicia, las regalías y los pretendidos privilegios de la Corona relativos a las Iglesias de sus posesiones de ultramar [...] no se ha consentido jamás que los nuncios, siquiera fuesen revestidos de facultades especiales por la Santa Sede, interviniesen lo más mínimo en las cosas eclesiásticas de las mencionadas diócesis y con motivo de alguna negociación se ha evitado siempre su mediación [la de los nuncios], prefiriendo tratarla directamente en Roma a través de la legación española. El rigor se llevaba hasta el extremo que los oficiales del Ministerio de Gracia y Justicia, encargados de los asuntos de ultramar, tenían prohibición expresa de visitar, incluso por mero cumplido al nuncio residente en Madrid si no fue con permiso del ministro [...] $]^{66}$

A estas razones para no tratar sobre las modificaciones del concordato con el gobierno, el nuncio alegó otras por las que consideró que no se sería suficiente para acabar con la práctica de que los vicarios fueran elegidos a propuesta de la autoridad civil y que ejercieran su jurisdicción eclesiástica sin la previa institución canónica. En primer lugar, porque no sólo debería excluirse el artículo referente a las circunscripciones diocesanas y otros semejantes -como señalaba la Congregación-, con lo cual la pretendida extensión del texto concordatario se limitaría a unos pocos artículos y, aún en este caso, debería hacerse con $\ll[. .$.$] diferencia$

$66 \ll[\ldots]$ Debbo innanzi tutto premettere, esser superiore ad ogni espressione la gelosia e tenacità del governo spagnolo nel sostenere per mezzo del così detto Consiglio delle Indie in addietro ed ora del Ministero di Grazia e Giustizia, le regalie ed i pretesi privilegi della Corona relativamente alle Chiese dei suoi possedimenti di oltremare [...] non si è mai consentito che i nunzi, seppure fossero rivestiti dalla Santa Sede di speciali facoltà, s'ingerissero menomamente in quanto riguardasse le cose ecclesiastiche delle rimentovate (sic) diocesi. Ed all'occasione di qualche negoziazione si è sempre evitata la loro mediazione, preferendo di trattarne direttamente in Roma coll'opera della legazione spagnola. Il rigore era portato a tal estremo, che gli ufficiali del Ministero di Grazia e Giustizia, incaricati della ponenza di oltremare, aveano espressa proibizione di visitare anche per mero complimento il nunzio residente in Madrid, seppur non fosse con previa licenza del Ministro [...]» (AA.EE.SS, Spagna I, pos. 361, fasc. 105, doc. 52. Despacho en clave $\mathrm{n}^{\circ} 352$ de Brunelli, Madrid, 13 de marzo de 1851, ff. 98v-99r). 
entre las iglesias de los dominios españoles en América y aquellos de Asia [...]» ${ }^{67}$. Por otra parte, porque el referido abuso no era el único, ni el más grave. En este sentido el nuncio escribió:

[...] Todo allí está en el más espantoso desorden como consecuencia de las prerrogativas y privilegios concedido a los Reyes Católicos en circunstancias que ahora no se verifican y por razones que ya no existen. Por decirlo en dos palabras en aquellas partes el capitán general, o sea el virrey, es el obispo. En estos términos fui unánimemente informado por monseñor Alameda, antes arzobispo de Cuba, ahora de Burgos, y por monseñor Lapuente (sic), antes obispo de Puerto Rico, ahora de Segovia. Peor andan las cosas en las islas Filipinas, según me han asegurado más eclesiásticos dignos de fe $[\ldots]^{68}$.

El gran mal de la Iglesia de los dominios españoles de ultramar: el patronato. Si se continuaba insistiendo en la extensión, se cerraría -en opinión del nuncio- «por así decirlo, el camino para entrar en negociaciones a su debido tiempo para corregirlos generalmente y regular la administración eclesiástica en el mejor modo posible» ${ }^{69}$. Con extender, por otra parte, sólo artículo 20 , no se habría remediado un abuso que no se debía atribuir a los cabildos, sino al gobierno que «invitaba», obligaba con la conocida real cédula de ruego y encargo a delegar la jurisdicción ordinaria en el nuevo obispo. El hecho de que en el artículo 44 del concordato aludiese a la extensión del mismo a los dominios de España sería suficiente para que aquellas cuestiones que por su naturaleza fueran similares al objeto tratado en el concordato pudiesen ser apeladas a él. Y concluía su exposición denunciando la razón, en última instancia, de la existencia de tales transgresiones en ultramar. De forma subrepticia, sin una acusación directa, apuntaba a la Santa Sede como responsable: la práctica desde los primeros tiempos de la conquista, asentada sobre la legitimación de las bulas y privilegios concedidos, había creado

$67 \ll[\ldots]$ differenza fra le Chiese de' domini spagnoli in America e quelli di Asia [...]» (ibid., f. 102r).

$68 \ll[\ldots]$ Tutto colà è nel più spaventoso disordine in grazia delle prerogative e privilegi accordati ai Re Cattolici in circostanze, che ora non si verificano, e per cause che più non sussistono. Per dirlo in due parole in quelle parti il capitan generale, ossia il viceré è il vescovo. In questi precisi termini ne fui concordemente informato da Monsignore Alameda prima arcivescovo di Cuba, ora di Burgos, e da Mg. Lapuente (sic), prima vescovo di Portorico, ora di Segovia. Anche peggiore è l'andamento delle cose nelle Isole Filippine secondo che mi hanno assicurato più ecclesiastici degni di fede [...]» (ibid., f. 102v) [La cursiva es nuestra].

$69 \ll[. .$.$] e chiusa, per così dire, la strada ad entrare a tempo debito in trattative per correggerli$ generalmente, e regolare l'amministrazione ecclesiastica nel miglior modo possibile [...]» (ibid., f. 103r). 
costumbre y la costumbre con el tiempo había sido reconocida ley, sin que la Santa Sede hubiese protestado lo contrario; éste era el ejemplo de lo que ocurría con la elección de los vicarios ${ }^{70}$.

Por tanto, sólo el artículo 29 de los 45 artículos que compusieron el Concordato que se refirió en concreto a la Iglesia de Ultramar y junto a él una nota diplomática, de 13 de marzo de 1851, en la que a duras penas el gobierno se comprometía a estudiar con la Santa Sede el problema de los vicarios en sede vacante.

\section{CONCLUSIÓN}

La firma del concordato el 26 de marzo 1851 dejó al margen a las diócesis ultramarinas de un texto normativo que, salvando los derechos del patronato real, dio una mayor autonomía a los obispos españoles y supuso una nueva organización de la iglesia en base a criterios de racionalización y de uniformización. Esta exclusión condenó a la Iglesias ultramarinas y particularmente a las antillanas a continuar sometidas a un patronato que, apoyándose en una continua reinterpretación de las bulas alejandrinas y de Julio II, supo legitimar una intervención cada vez mayor de la autoridad civil en los asuntos del gobierno temporal de la Iglesia en aquellos territorios ante un silencio muchas veces cómplice de Roma, que los toleró en pro bono pacis, mientras que en las islas se daban abiertos enfrentamientos entre ambas autoridades. Queremos concluir advirtiendo que esta especificidad selló desde el punto de vista eclesiástico la misma excepcionalidad que en lo político el gobierno había decretado en 1836, cuando se estableció que las Antillas españolas serían gobernadas por leyes especiales y que sancionó un año después con la exclusión de las Cortes de los diputados antillanos.

70 Ibid., ff. $103 \mathrm{v}-105 \mathrm{v}$. 



\section{HISTORIOGRAFÍA Y BIBLIOGRAFÍA}


